\title{
LA FAMILIA Y EL MATRIMONIO IGUALITARIO EN EL PERÚ. UNA LECTURA DINÁMICA DE LA CONSTITUCIÓN POLÍTICA DE $1993^{1}$
}

\author{
FAMILY AND MARRIAGE EQUALITY IN PERÚ. A DYNAMIC READING \\ OF THE 1993 POLITICAL CONSTITUTION
}

Rafael Rodríguez Campos ${ }^{2}$

Resumen:

El autor realiza un análisis desde el punto de vista constitucional sobre el reconocimiento e inscripción del matrimonio de personas del mismo sexo a raíz de una petición realizada ante la entidad administrativa correspondiente.

Palabras clave: matrimonio igualitario, matrimonio, familia, Derecho Constitucional.

Abstract: The author analyzes, from a constitutional point of view, the recognition and registration of same-sex marriages as a result of a request made to the corresponding administrative entity.

Keywords: marriage equality, marriage, family, Constitutional Law.

1 Este artículo ha sido elaborado íntegramente sobre la base de otros de mi autoría:

- Kelsen y el Matrimonio Igualitario en el Perú. Autopsia a la Sentencia Ugarteche Galarza. En: Diálogo con la Jurisprudencia. Tomo 222, marzo 2017. Editorial Gaceta Jurídica.

- El matrimonio igualitario y la familia en el Perú (Segunda Parte). Columna publicada el día 13 de marzo de 2017 en el Diario Clarín (Cajamarca).

- El matrimonio igualitario y la familia en el Perú (Primera Parte). Columna publicada el día 06 de marzo de 2017 en el Diario Clarín (Cajamarca).

- Las parejas del mismo sexo sí podrán adoptar niños. Cuando la solicitud recaiga en el hijo del compañero (a) permanente. En: Gaceta Constitucional y Procesal Constitucional. Tomo 88, abril 2015. Editorial Gaceta Jurídica.

- Chile aprueba el acuerdo de vida en pareja para heterosexuales y homosexuales: ¿Se aprobará en el Perú la unión civil? En: Gaceta Constitucional y Procesal Constitucional. Tomo 87, marzo 2015. Editorial Gaceta Jurídica

- Uniones civiles homosexuales, religión y política. En: Gaceta Constitucional. Tomo 71, noviembre 2013. Editorial Gaceta Jurídica.

2 Abogado por la Pontificia Universidad Católica del Perú (PUCP). Cuenta con un Título de Post Grado y estudios de maestría en Ciencia Política y Gobierno (Sistema Electoral, Sistema de Partidos y Sistema de Gobierno) en la Escuela de Gobierno y Políticas Públicas de la PUCP. Cuenta con un Título de Especialista en Justicia Constitucional, Interpretación y Aplicación de la Constitución en la Universidad Castilla - La Mancha (Toledo - España). Es Candidato a Máster en Derecho Constitucional en la Universidad Castilla - La Mancha (Toledo-España). Con experiencia docente en Derecho Constitucional (Facultad de Derecho de la PUCP), Teoría Política (Escuela de Gobierno y Políticas Públicas de la PUCP) y Derecho Electoral (Facultad de Derecho de la USMP). Es profesor de Ciencia Política e Historia de las Ideas Políticas en la Facultad de Derecho de la Universidad San Martín de Porres. Miembro de la Sociedad de Debates de la Facultad de Derecho de la Universidad San Martín de Porres. Miembro del Centro de Estudios Internacionales de la Facultad de Derecho de la Universidad San Martín de Porres. Miembro de la Asociación Peruana de Derecho Constitucional. Asesor del Gabinete de Asesores de la Jefatura Nacional del Registro Nacional de Identificación y Estado Civil (RENIEC). Escribe y publica artículos sobre temas de Derecho Constitucional, Derechos Humanos y Ciencia Política en medios especializados y periodísticos. 


\section{INTRODUCCIÓN}

En el Perú, luego de que el Séptimo Juzgado Constitucional de Lima, declarara fundada la demanda de amparo interpuesta por el ciudadano Oscar Ugarteche Galarza contra el RENIEC, ordenando que este organismo constitucional "reconozca e inscriba" el matrimonio celebrado entre él y su esposo Fidel Aroche Reyes, celebrado en la ciudad de México, se ha reabierto el debate sobre la familia y el matrimonio igualitario.

Al respecto, hemos escuchado decir a una serie de figuras provenientes del sector más conservador (religioso) de nuestra sociedad, que el "único modelo de familia que el Estado reconoce es el que está relacionado con el matrimonio". Es más, quienes se oponen a la aprobación del matrimonio igualitario usan justamente este argumento para hacernos creer que si una familia no está compuesta por la unión entre un varón y una mujer (para fines básicamente reproductivos) entonces no puede ser considerada como tal. En otras palabras, para estas personas, el matrimonio igualitario debe ser rechazado ya que pone en peligro el "único modelo de familia que el Estado reconoce".

Como es posible intuir, este argumento es absolutamente falso y carece de todo sustento (desde el sociológico hasta el constitucional). Sin embargo, y dado que las mentiras proferidas por este sector van en aumento, considero necesario reflexionar sobre la relación existente entre la familia y el matrimonio igualitario en el Perú.

Por lo tanto, en este breve artículo demostraré dos cosas: 1) Que "la Constitución no señala que el único modelo de familia que el Estado reconoce es el que está relacionado con el matrimonio"; y 2) Que "el matrimonio igualitario no atenta contra la familia, como algunas personas maliciosamente lo vienen sosteniendo". Finalmente, expondré algunas consideraciones constitucionales que respaldan la aprobación de una Ley que reconozca el matrimonio igualitario en nuestro país.

\section{La familia en la Constitución Política del Perú}

La familia fue consagrada a nivel constitucional (en occidente) recién en la primera mitad del siglo XX, siendo la Constitución de Weimar de 1919 (Alemania) la primera en reconocer expresamente el rol protector del Estado para con la familia. 
Ahora bien, y como es fácil suponer, en aquellos años (han transcurrido casi 100 años desde ese entonces) se identificaba al matrimonio como la única fuente creadora de familia. Se trataba, como bien lo apunta la doctrina, de un modelo de familia matrimonial, tradicional nuclear, en donde el varón era el cabeza de la familia dedicado a cubrir los gastos familiares y la mujer realizada necesariamente las labores del hogar.

Pues bien, esta manera de concebir a la familia se fue extendiendo a nivel mundial luego de la segunda guerra mundial, expansión que también ocurrió en nuestra región en países como Colombia, Chile, Costa Rica, Paraguay y Venezuela.

\section{La familia en los tratados sobre derechos humanos}

A su turno, a nivel internacional, la familia también ha sido objeto de reconocimiento y protección. Así por ejemplo, el Pacto Internacional de Derechos Civiles y Políticos se refiere a la familia como "elemento natural y fundamental de la sociedad", sujeta a la protección del Estado y la sociedad. Del mismo modo, la Convención Americana de Derechos Humanos establece que la familia debe ser protegida por el Estado y la sociedad.

\section{La Familia en la Constitución histórica del Perú}

Pero ya hablando específicamente de nuestro país, nuestra historia republicana nos dice que fue la Constitución de 1933 la que por primera vez reconoció expresamente la tutela de la familia. Esta Constitución señaló en su momento que "el matrimonio, la familia y la maternidad estaban bajo la protección de la ley". Luego, la Constitución de 1979, conceptualizó a la familia como una "sociedad natural y una institución fundamental de la Nación". Así llegamos a la Constitución de 1993, norma fundamental vigente que reconoce a la familia como un instituto "natural y fundamental de la sociedad".

\section{La familia en la Constitución Política de 1993}

Como podemos apreciar, y más allá de la vocación tutelar puesta de manifiesto en nuestras Constituciones desde el año 1933, queda claro que el texto constitucional no establece o define un concepto único de familia. ¿Puede ser este un olvido del constituyente? No, lo que ocurre es que la Constitución no pretendió jamás reconocer un modelo específico de familia por lo complejo que resulta definir a una institución "natural" como ésta, 
siempre sujeta al devenir histórico de los nuevos tiempos. Es por eso que, como bien lo señaló nuestro Tribunal Constitucional (Ver Sentencia 065722006-PA/TC), el instituto de la familia no debe relacionarse necesariamente con el matrimonio, como ocurría con el Código Civil de 1936, que establecía una inconstitucional diferencia entre los hijos "legítimos" y "no legítimos", por ejemplo.

\section{La familia como institución natural}

Entonces, sostener que la familia es una institución natural (no impertérrita) supone reconocer su carácter ético y social, es decir, la familia se encuentra inevitablemente a merced de los nuevos tiempos, así lo ha expuesto correctamente la Comisión de Derechos Humanos de las Naciones Unidas en un informe del año 1990, al reconocer la amplitud del concepto de familia, además de sus diversos tipos. En este mismo documento, la Comisión subrayó la naturaleza dinámica de la familia al afirmar que hechos como la inclusión social y laboral de la mujer, la regulación del divorcio y su alto grado de incidencia, las migraciones hacia las ciudades, entre otros aspectos, han significado un cambio profundo (quiebre) en la estructura de la familia tradicional nuclear, conformada alrededor de la figura del "pater familias".

Es más, producto de estos cambios, en la actualidad se han generado familias con estructuras distintas a la tradicional como aquellas surgidas de las uniones de hecho, las monoparentales o las que la doctrina denomina familias reconstituidas. Todas ellas son familias que no encajan dentro del modelo tradicional, pero que igualmente y gracias a su unidad se convierten en un espacio fundamental para el desarrollo integral de cada uno de sus miembros, encargándose de la transmisión de valores, conocimientos y tradiciones culturales. En suma, como lo señala el Tribunal Constitucional en la jurisprudencia antes referida, todas estas familias, sin distinción alguna, son un agente primordial del desarrollo social.

Finalmente, citando al propio Tribunal Constitucional, queda claro que, sin importar el tipo de familia ante la que se esté, ésta será merecedora de protección frente a las injerencias que puedan surgir del Estado y de la sociedad. Por tanto, no puede argumentarse que el Estado solo tutela a la familia matrimonial, tomando en cuenta que existe una gran cantidad de familias extramatrimoniales. Además, el instituto familia trasciende al del matrimonio, ya que incluso puede darse la situación de que extinguido dicho vínculo, la familia persista. 


\section{La familia y el matrimonio igualitario}

Ahora bien, una vez demostrado que nuestra Constitución no señala que el único modelo de familia que el Estado deba reconocer es el que está relacionado con el matrimonio, corresponde demostrar que el matrimonio igualitario no atenta contra la familia, y tampoco pone en peligro la conservación de la especie humana, como algunos grupos conservadores y religiosos lo vienen sosteniendo maliciosamente.

Al respecto, tomando como referencia lo expuesto en el punto anterior, considero que nuestro Tribunal Constitucional acierta cuando señala que los nuevos tiempos han generado familias con estructuras distintas a la tradicional como son las surgidas de las uniones de hecho, las monoparentales o las denominadas reconstituidas. De hecho, son estas últimas las que han ganado terreno en los últimos años. Como bien lo señaló el Tribunal, se trata de familias ensambladas cuya estructura familiar se origina en el matrimonio o la unión concubinaria de una pareja en la cual uno o ambos de sus integrantes tienen hijos provenientes de una relación previa.

\section{Los nuevos modelos de familia exigen una precisión legislativa}

Ahora bien, resulta claro que estos nuevos modelos de familia deben ser desarrollados a nivel legislativo, así lo señaló en su oportunidad María Gonzáles Luna, al afirmar que el Tribunal con sus fallos estaba visibilizando los problemas surgidos a partir de la formación de nuevas familias, ya que si bien sabemos que en el Perú hay muchos hogares distintos a la familia tradicional, las cifras no lo reflejan. Por ejemplo, dice la autora, en los censos hechos por el INEI, no sabemos qué relación de parentesco corresponde a los hijastros, ¿son considerados otros parientes o no parientes? En cualquiera de las dos categorías se mezclan con sujetos que no tienen los mismos derechos y necesidades que ellos.

Por tanto, refiere esta autora, el Congreso de la República debe incluir de manera expresa a las nuevas familias y los derechos de éstas y de sus miembros en la legislación, tanto en materia civil como penal. En cuanto a la primera, por ejemplo, el artículo $233^{\circ}$ del Código Civil señala que la regulación jurídica de la familia tiene por finalidad contribuir a su consolidación y fortalecimiento en armonía con los principios y normas proclamados en la Constitución Política. Por lo que la legislación que se dicte sobre esta materia debe adecuarse a lo señalado por el máximo intérprete de la Constitución. 


\section{El fin de la familia no es la procreación}

En esa misma línea, el Tribunal también ha señalado -este es otro acierto-, que la familia no puede concebirse únicamente como una institución en cuyo seno se materialice la dimensión generativa de la especie. La familia es también la unidad encargada de transmitir valores éticos, cívicos y culturales. Es justamente esa unidad la que la convierte en un espacio primordial para el desarrollo integral de cada uno de sus miembros, la transmisión de valores, conocimientos, tradiciones culturales y lugar de encuentro intra e intergeneracional, es pues un agente primordial del desarrollo social, así lo expone el Tribunal, y así debería entenderse el concepto de familia en pleno siglo XXI.

\section{Las personas del mismo sexo tienen todo el derecho a formar una familia}

Entonces, ¿pueden las personas del mismo sexo formar una familia? Claro que sí, no solo porque como hemos visto no existe un único modelo de familia (matrimonial) sino porque los nuevos tiempos nos obligan a ampliar el concepto y reconocer nuevas formas de unión (concubinatos, familias ensambladas, reconstituidas, familias de segundas nupcias, etcétera), quedando claro que la familia no tiene como única finalidad la procreación.

En tal sentido, no existe razón alguna para creer que las personas del mismo sexo no puedan formar un hogar familiar, sobre todo cuando se trata de personas que llevan su vida como si fuesen cónyuges, compartiendo intimidad en un contexto de amor, unidos por un fuerte lazo afectivo. De hecho, las parejas homosexuales -al igual que las parejas heterosexualestambién basan su unión en principios de fidelidad, cariño y respeto mutuo. En otras palabras, llevan una vida igual a la que presentan las parejas heterosexuales.

Por tanto, si estas parejas están sujetas a las mismas obligaciones que las parejas heterosexuales, ¿por qué razón no podrían formar una familia al amparo de una Ley que apruebe el matrimonio igualitario? Como podrán darse cuenta, no existe razón constitucional alguna para oponerse al matrimonio igualitario que no sea la homofobia, el machismo, el conservadurismo o el fanatismo religioso.

\section{Los fantasmas inventados}

Como habrán podido apreciar, el concepto de familia ha ido cambiando con el paso del tiempo. Eso es algo lógico teniendo en consideración que se trata de un instituto natural sujeto al devenir del espacio y tiempo histórico. 
Hoy en día el modelo familiar tradicional ya no es el mayoritario, eso no quiere decir que haya entrado en crisis, simplemente que el concepto de familia se ha ampliado y nuevos modelos o tipos familiares surgen producto de factores sociales, económicos y culturales, que ninguna fe o religión está en condiciones de frenar.

Por eso, con el mayor de los respetos, a quienes se oponen al matrimonio igualitario, debo decirles que su oposición es antojadiza y carente de sustento. Ellos dicen que el matrimonio igualitario acabará con la familia tradicional, elevando el número de parejas homosexuales y lésbicas, como si una Ley tuviese el poder para determinar la identidad u orientación sexual de las personas. Para ellos, sectores conservadores que basan su postura en el dogmatismo religioso más intolerante, el matrimonio igualitario marcará el inicio del fin de nuestra especie.

Sí, así como lo leen, estos sectores creen que "por moda o imitación" las personas -incluyendo a los heterosexuales- optarán por contraer nupcias con personas del mismo sexo. Yo me pregunto: ¿En serio estos peruanos y peruanas creen en tan delirantes argumentos? Espero que no. Quiero creer que no.

A estos sectores habría que decirles que "el modelo de familia tradicional" ya no es el hegemónico, eso no quiere decir que no estén en su derecho de promoverlo y buscarlo como parte de su opción personal de vida, lo que no pueden hacer es imponer su particular visión de las cosas sobre la de los demás, como si todos estuviésemos de acuerdo con ellos, como si todos creyésemos en que Adán y Eva fueron nuestros primeros padres, como si el modelo de familia bíblico instaurado hace más de 2000 mil años no hubiese sido rebasado por la fuerza de la historia.

Alguien dijo que sólo Dios y los idiotas no cambian. Yo no le tengo miedo al cambio, ni al político ni al jurídico, más cuando este cambio busca reconocer derechos y libertades a más personas. Nadie en su sano juicio puede creer que el matrimonio igualitario busca acabar con las uniones heterosexuales. Las parejas heterosexuales se seguirán uniendo en matrimonio si ellas así lo quieren. Eso no dejará de ocurrir. Así que por favor, dejemos de usar mentiras y falsedades. Dejemos de lado los odios que tanto daño le hacen a nuestra convivencia. Dejemos que las personas sean felices ejerciendo su libertad en condiciones de igualdad y sin discriminación de ningún tipo. 


\section{Consideraciones a favor del matrimonio igualitario}

$\mathrm{Al}$ respecto, considero necesario hacer referencia a los argumentos (que hago míos) que en su momento reseñé en un artículo de mi autoría sobre el contenido y alcances de la referida sentencia emitida en el caso Ugarteche Galarza, tomando como base la línea de razonamiento expuesta por el Sétimo Juzgado Constitucional de Lima.

Ahora bien, con el ánimo de darle orden a los argumentos a favor del matrimonio igualitario, utilizaré una metodología de preguntas y respuestas, la misma que espero permita una mejor comprensión sobre la materia.

\section{¿Por qué el demandante interpuso demanda de Amparo contra el RENIEC?}

Al respecto, el Juzgado señala que el 12 de enero de 2012, el demandante solicitó ante el RENIEC la inscripción de su matrimonio (celebrado en México) en el registro correspondiente. Luego, el RENIEC rechazó su pretensión. Frente a esa negativa, el demandante interpuso la demanda de Amparo, argumentando que se estaba vulnerando su derecho constitucional a la igualdad y a la no discriminación.

\section{¿Por qué el RENIEC rechazó la pretensión del demandante?}

Al respecto, el Juzgado señala que el RENIEC rechazó la pretensión del demandante, bajo los siguientes argumentos:

Primero, porque el artículo $234^{\circ}$ del Código Civil, señala que entre los elementos estructurales del matrimonio se encuentra la diversidad de sexo y responsabilidad entre los contrayentes.

Segundo, porque el referido artículo señala que el matrimonio es la unión voluntariamente concertada entre varón y una mujer, por lo tanto, no existe en nuestra legislación respaldo normativo para el matrimonio entre personas del mismo sexo.

¿Por qué el $7^{\circ}$ Juzgado admitió a trámite y declaró procedente la demanda?

Al respecto, el Juzgado considera que en este caso era importante identificar el conjunto de derechos constitucionales que pueden haberse visto amenazados o vulnerados por la negativa del RENIEC a proceder con la inscripción del matrimonio celebrado por el demandante. 
En ese sentido, la lista de derechos constitucionales identificada por el Juzgado es la siguiente: derecho a la dignidad, derecho al libre desarrollo y bienestar, derecho a la igualdad, derecho a la intimidad personal y familiar, entre otros.

Luego, en la sentencia, se advertirá que el derecho constitucional que "específicamente" busca tutelar el Juzgado -declarando fundada la demanda de Amparo- es el derecho a la igualdad y a la no discriminación.

¿Por qué el $7^{\circ}$ Juzgado consideró necesario identificar la lista de derechos constitucionales que pueden haberse visto amenazados o vulnerados por la negativa del RENIEC a proceder con la inscripción del matrimonio celebrado por el demandante?

Al respecto, el Juzgado hace esta identificación, con la finalidad de poder determinar (atendiendo al argumento del RENIEC), si el artículo $234^{\circ}$ del Código Civil, referido al matrimonio, es contrario o no a nuestra Constitución.

¿Por qué es importante analizar la constitucionalidad del artículo $234^{\circ}$ del Código Civil para la resolución de este caso?

Al respecto, el Juzgado señala que si bien es cierto nuestra Constitución Política, en su artículo $4^{\circ}$, establece que la forma del matrimonio se regula por la ley, también es cierto que dichas leyes no pueden ser contrarias a la propia Constitución, puesto que según nuestra conocida Pirámide de Kelsen, nuestra Carta Magna es la norma de mayor jerarquía, por lo que en caso de conflicto con otros dispositivos legales, tendrá que prevalecer la primera.

¿Por qué el Juzgado, para resolver el caso, hace referencia explícita a la legislación y jurisprudencia internacional en materia de protección de los derechos humanos? ¿Acaso no bastaba con analizar el artículo $234^{\circ}$ de nuestro Código Civil a la luz de los derechos reconocidos en la Constitución Política?

Al respecto, el Juzgado consideró necesario recordar lo siguiente:

Primero, lo señalado en la Cuarta Disposición Final y Transitoria de nuestra Constitución Política, referida a la interpretación de los derechos constitucionales: Las normas relativas a los derechos y a las libertades que la Constitución reconoce se interpretan de conformidad con la Declaración Universal de Derechos Humanos y con los tratados y acuerdos internacionales sobre las mismas materias ratificados por el Perú (el subrayado es nuestro). 
Segundo, lo señalado en el artículo V del Título Preliminar del Código Procesal Constitucional, también referido a la interpretación de los derechos constitucionales: El contenido y alcances de los derechos constitucionales protegidos por los procesos regulados en el presente Código deben interpretarse de conformidad con la Declaración Universal de Derechos Humanos, los tratados sobre derechos humanos, así como de las decisiones adoptadas por los tribunales internacionales sobre derechos humanos constituidos según tratados de los que el Perú es parte (el subrayado es nuestro).

¿Cuál es la materia constitucionalmente relevante que el $7^{\circ}$ Juzgado identifica como trascendental para resolver este caso?

Al respecto, el Juzgado considera que la pregunta que debe responderse para resolver este caso es la siguiente: ¿Existe una razón objetiva y razonable para no reconocer el matrimonio homosexual celebrado por el señor Oscar Ugarteche Galarza en la ciudad de México?

En otras palabras, lo que el Juzgado busca analizar es si la denegatoria del RENIEC, amparada en el artículo $234^{\circ}$ del Código Civil, es acorde con la Constitución Política, la misma que señala que los derechos y libertades reconocidos en su seno, deben ser interpretados de conformidad con los tratados y acuerdos Internacionales ratificados por el Perú.

Sobre este punto, es importante señalar que el Juzgado, al momento de resolver la pregunta antes formulada, también toma en cuenta lo dispuesto en el Código Procesal Constitucional, el mismo que señala que el contenido y alcances de los derechos constitucionales protegidos por los procesos constitucionales deben interpretarse de conformidad con la Declaración Universal de Derechos Humanos, los tratados sobre derechos humanos, así como de las decisiones adoptadas por los tribunales internacionales sobre derechos humanos constituidos según tratados de los que el Perú es parte.

¿Cuáles son los tratados ylo acuerdos Internacionales ratificados por el Perú que el $7^{\circ}$ Juzgado refiere para fundamentar su decisión y declarar fundada la demanda de Amparo?

Al respecto, el Juzgado alude expresamente a las siguientes normas del Derecho Internacional de los Derechos Humanos:

Primero, el primer párrafo del artículo $2^{\circ}$ de la Declaración Universal de Derechos Humanos, en adelante DUDH, que establece: Toda persona tiene los derechos y libertades proclamados en esta Declaración, sin distinción 
alguna de raza, color sexo, idioma, religión, opinión, política o de cualquier otra índole, origen nacional o social, posición económica, nacimiento $\underline{\mathrm{o}}$ cualquier otra condición (...) (el subrayado es nuestro).

Sobre este punto, el Juzgado consideró oportuno hacer referencia a los Principios de Yogyakarta, los cuales extienden explícitamente la DUDH a las personas homosexuales, bisexuales, transexuales y transgénero, cuyos derechos ya estaban incluidos implícitamente en el artículo $2^{\circ}$ de la mencionada Declaración Universal bajo los genéricos «o de cualquier otra índole» $\mathrm{y}$ «o cualquier otra condición».

Asimismo, el Juzgado destaca que los referidos principios son un documento que recoge una serie de principios relativos a la orientación sexual e identidad de género, con la finalidad de orientar la interpretación y aplicación de las normas del Derecho Internacional de los Derechos Humanos, estableciendo unos estándares básicos, para evitar los abusos y dar protección a los derechos humanos de las personas lesbianas, gais, bisexuales y transexuales.

Segundo, el artículo $16^{\circ}$ de la DUDH que establece que: Los hombres y mujeres, a partir de la edad núbil, tienen derecho sin restricción alguna por motivos de razón nacionalidad o religión, a casarse y fundar una familia; y disfrutarán de iguales derechos en cuanto al matrimonio, durante el matrimonio y en caso de disolución del matrimonio. Solo mediante libre y pleno consentimiento de los futuros esposos podrá contraerse el matrimonio. La familia es el elemento natural y fundamental de la sociedad y tiene derecho a la protección de la sociedad y del Estado (el subrayado es nuestro). Sobre este punto, el Juzgado "justamente" invocando los Principios de Yogyakarta, afirma que el derecho contemplado en el referido artículo $16^{\circ}$ de la DUDH, se aplica también a las personas homosexuales, bisexuales, transexuales y las personas transgénero.

Tercero, el numeral 2, del artículo $23^{\circ}$ del Pacto Internacional de Derechos Civiles y Políticos, que establece: El derecho del hombre y de la mujer a contraer matrimonio y a fundar una familia si tienen edad para ello (el subrayado es nuestro).

Cuarto, el artículo VI de la Declaración Americana de los Derechos y Deberes del Hombre, que establece: Toda persona tiene derecho a construir familia; el elemento fundamental de la sociedad, y a recibir protección para ella (el subrayado es nuestro). 
Quinto, el numeral 2, artículo $17^{\circ}$ de la Convención Americana Sobre Derechos Humanos, en adelante $\mathrm{CADH}$, que establece: Se reconoce el derecho del hombre y la mujer a contraer matrimonio y a fundar una familia si tienen la edad y las condiciones requeridas para ello y por las leyes internas, en la medida que éstas no afecten el principio de no discriminación establecido en esta Convención (el subrayado es nuestro).

Finalmente, el Juzgado hace un especial énfasis en el artículo $24^{\circ}$ de la $\mathrm{CADH}$, que establece: Todas las personas son iguales ante la ley. En consecuencia, tienen derecho sin discriminación a la igual protección de la ley (el subrayado es nuestro).

¿Luego de revisar las normas del Derecho Internacional de los Derechos Humanos (para el control de convencionalidad del artículo 234 del Código Civil, por ejemplo) a qué conclusión llega el $7^{\circ}$ Juzgado?

Al respecto, el Juzgado, al amparo de lo señalado por el Tribunal Constitucional del Perú sobre la naturaleza dinámica de instituciones naturales como la familia o artificiales (jurídicas) como el matrimonio, afirma lo siguiente:

Primero, que desde una perspectiva constitucional, debe indicarse que la familia, al ser un instituto natural, se encuentra inevitablemente a merced de los nuevos contextos sociales. Es más, que han sido los cambios sociales y jurídicos tales como la inclusión social y laboral de la mujer, la regulación del divorcio y su alto grado de incidencia, las grandes migraciones hacia las ciudades, entre otros aspectos, los que generaron un cambio en la estructura de la familia tradicional nuclear, conformada alrededor de la figura del padre de familia. Producto de ello, apunta el Juzgado, se han generado familias con estructuras distintas a la tradicional, como son las surgidas de las uniones de hecho, las monopaternales o las que en doctrina se han denominado familias reconstituidas (el subrayado es nuestro).

Segundo, que si bien es cierto el derecho a contraer matrimonio es diferente al de formar una familia, no debe existir impedimento para que pueda formarse una familia partiendo de un matrimonio homosexual, razón por la cual el Juzgado considera que un homosexual está en todo se derecho de poder formar una familia, esto en virtud de las nuevas exigencias que se han ido presentando en los últimos tiempos, referidas a los derechos de las parejas homosexuales (el subrayado es nuestro). 
¿Por qué resulta relevante destacar la naturaleza dinámica de las instituciones naturales y/o de las instituciones jurídicas en general, al momento de llevar a cabo un ejercicio de interpretación constitucional para este caso?

Al respecto, el Juzgado, con la finalidad de justificar la necesidad de llenar de contenido a las normas constitucionales y legales, tornándolas compatibles con los nuevos tiempos y exigencias que la realidad social le impone a los operadores del Derecho, en especial a las Cortes, hace mención al concepto de "interpretación evolutiva", desarrollado por el Tribunal Constitucional Español (Caso 182/2012, 06 de noviembre de 2012), en los siguientes términos:

Primero, que la "Constitución es árbol vivo" que, a través de una «interpretación evolutiva», se acomoda a las realidades de la vida moderna como medio para asegurar su propia relevancia y legitimidad, y no sólo porque se trate de un texto cuyos grandes principios son de aplicación a supuestos que sus redactores no imaginaron, sino también porque los poderes públicos, y particularmente el legislador, van actualizando esos principios paulatinamente, y porque el Tribunal Constitucional, cuando controla el ajuste constitucional de esas actualizaciones, dota a las normas de un contenido que permita leer el texto constitucional a la luz de los problemas contemporáneos, y de las exigencias de la sociedad actual a que debe dar respuesta la norma fundamental del ordenamiento jurídico a riesgo, en caso contrario, de convertirse en letra muerta (el subrayado es nuestro).

Segundo, que la aplicación de la interpretación evolutiva, sin recurrir a otras técnicas interpretativas, se relaciona directamente con las denominadas "modificaciones tácticas de la Constitución", que se encuentran en la fase media entre el ordenamiento formal y su evolución real y continua, que implica una evolución, o avance, que no obliga a una modificación formal del texto constitucional, ni a la introducción de preceptos constitucionales nuevos, es decir, la evolución social muta la Constitución por vía interpretativa (el subrayado es nuestro).

Como se pude apreciar, este enfoque conceptual, no hace otra cosa que reforzar lo que el Juzgado ya había señalado: que si bien es cierto el derecho a contraer matrimonio es diferente al de formar una familia, no debe existir impedimento para que pueda formarse una familia partiendo de un matrimonio homosexual, esto en virtud de las nuevas exigencias que se han ido presentando en los últimos tiempos, referidas a los derechos de las parejas homosexuales (el subrayado es nuestro). 
¿Existen decisiones internacionales vinculantes para el Estado peruano que refuerzan la línea de razonamiento e interpretación constitucional expuesta por el Juzgado en este caso?

Al respecto, el Juzgado ha considerado necesario hacer referencia a diferentes casos en los cuales los Organismos Internacionales, cuyas decisiones son vinculantes para el Estado peruano, como el Comité de Derechos Humanos de las Naciones Unidas (Caso 488/1992) y la Corte Interamericana de Derechos Humanos (Caso Duque vs Colombia, y Caso Atala Riffo y Niñas vs Chile), se han pronunciado sobre los derechos de las parejas homosexuales, y su relación con el derecho a la igualdad y el principio de no discriminación.

Primero, el Juzgado recuerda el Caso Tonnen contra Australia, en virtud del cual en el año 1994 por primera vez el Comité se posicionó respecto a los derechos de la comunidad LGTB, indicando que en el Pacto Internacional de Derechos Civiles y Políticos se recoge que las leyes contra la homosexualidad son una violación de los derechos humanos.

Segundo, el Juzgado refiere el caso Duque vs Colombia, en el cual la Corte (Considerando $\mathrm{N}^{\circ}$ 104) estableció que la orientación sexual y la identidad de género de las personas son categorías protegidas por la Convención. Por ello, está proscrita por la Convención cualquier norma, acto o práctica discriminatoria basada en la orientación sexual de la persona (el subrayado es nuestro). Por tanto, ninguna norma, decisión o práctica de derecho interno, sea por parte de autoridades estatales o por particulares, pueden disminuir o restringir, de modo alguno, los derechos de una persona a partir de su orientación sexual (el subrayado es nuestro).

En esa misma línea, en este caso, la Corte (Considerando $\mathrm{N}^{\circ} 105$ ) proscribe la discriminación, en general, incluyendo en ello categorías como las de la orientación sexual la que no puede servir de sustento para negar o restringir ninguno de los derechos establecidos en la Convención (el subrayado es nuestro), ya que dicha práctica sería contraria al mandato consagrado en el artículo 1.1 de la propia Convención.

Tercero, el Juzgado alude al caso Atala Riffo y Niñas vs Chile, en el cual la Corte señaló que la falta de un consenso al interior de algunos países sobre el respeto pleno por los derechos de las minorías sexuales no puede ser considerado como un argumento válido para negarles o restringirles sus derechos humanos o para perpetuar y reproducir la discriminación histórica y estructural que estas minorías han sufrido (el subrayado es nuestro). 
Sobre este punto, la Corte afirma que el hecho de que ésta pudiera ser materia controversial en algunos sectores y países, y que no sea necesariamente materia de consenso no puede conducir al Tribunal a abstenerse de decidir, pues al hacerlo debe remitirse única y exclusivamente a las estipulaciones de las obligaciones internacionales contraídas por decisión soberana de los Estados a través de la Convención (el subrayado es nuestro).

Cuarto, el Juzgado menciona lo establecido por el Comité de Derechos Económicos, Sociales y Culturales en su Observación General N ${ }^{\circ}$ 20, sobre que "cualquier otra condición social", tal y como se recoge en el artículo 2.2 del Pacto Internacional de Derechos Económicos, Sociales y Culturales, se incluye la orientación sexual. Por tanto, los Estados partes deben cerciorarse de que las preferencias sexuales de una persona no constituyan un obstáculo para hacer realidad los derechos que reconoce el Pacto, por ejemplo, a los efectos de acceder a la pensión de viudez. La identidad de género también se reconoce como motivo prohibido de discriminación (el subrayado es nuestro).

Finalmente, el Juzgado, trae a colación uno de los casos más importantes resueltos por lajurisdicción comparada.Hablo, específicamente, del Caso Obergefell vs Hodges, resuelto por la Corte Suprema de los Estados Unidos (5 votos contra 4 votos), mediante el cual se legalizó el matrimonio del mismo sexo.

En este caso, que en estricto no resulta vinculante para el Estado peruano, pero que sí evidencia el giro jurisprudencial que las Cortes más importantes del mundo están dando sobre esta materia, el Tribunal Norteamericano señaló que será inconstitucional que los estados prohíban el reconocimiento de este tipo de uniones o la consecución del matrimonio entre parejas del mismo sexo en sus territorios (el subrayado es nuestro).

Es más, la Corte señaló que es degradante impedir que parejas del mismo sexo formen parte de una institución central de la sociedad de la nación, porque ellos también pueden aspirar a los propósitos trascendentales del matrimonio (el subrayado es nuestro).

Por tanto, afirma la Corte, si bien la limitación del matrimonio a parejas del sexo opuesto puede haber parecido justa y natural, hoy su inconsistencia con el significado principal del derecho fundamental al matrimonio se hace manifiesta (el subrayado es nuestro). 
Entonces, a la luz de lo antes expuesto: ¿Existe una razón objetiva y razonable para no reconocer el matrimonio celebrado por el señor Oscar Ugarteche Galarza en la ciudad de México?

Al respecto, el Juzgado, luego de la revisión de las normas del Derecho Internacional de los Derechos Humanos y de las decisiones internacionales vinculantes para el Estado peruano emitidas por los organismos internacionales de protección de los Derechos Humanos (recordar las frases subrayadas),considera que la única razón por la cual se ha fundamentado la denegación del reconocimiento del matrimonio celebrado por el demandante en el extranjero, es porque fue celebrado entre personas homosexuales, no constituyendo un argumento razonable y objetivo, por lo que resulta altamente discriminatorio y contrario tanto a nuestra Constitución, como a todas las normas y decisiones del Derecho Internacional de los Derechos Humanos, referidas por el Juzgado en la sentencia.

\section{¿El Juzgado hace referencia a la regulación del matrimonio igualitario en la} legislación comparada?

Al respecto, el Juzgado consideró pertinente (luego veremos la importancia de este apunte) recordar el avance internacional en el reconocimiento del derecho de las parejas homosexuales a contraer matrimonio.

El proceso se inició en 2001, año en el cual Países Bajos reconoció legalmente el matrimonio para parejas homosexuales (también llamado matrimonio igualitario). Luego, la evolución ha sido la siguiente, anota el Juzgado:

- $\quad$ En Bélgica, el matrimonio entre personas del mismo sexo entró en vigor el 30 de enero de 2003.

- $\quad$ En España la Ley que reconoce el derecho de las parejas del mismo sexo al matrimonio entró en vigor el 3 de julio de 2005.

- $\quad$ En Canadá, la Ley de matrimonios homosexuales se hizo efectiva el 20 de julio de 2005. Fue el primer país del continente americano que lo legaliza.

- $\quad$ En Sudáfrica, una sentencia del Tribunal Constitucional de Sudáfrica dictaminó en 2005 que era injustificable la discriminación basada en 
la orientación sexual y dio un plazo de 12 meses al Gobierno para que modificara la Ley Nacional de Matrimonio sustituyendo las palabras marido o esposa por la palabra cónyuges.

- $\quad$ En Noruega la Ley que establece el matrimonio entre personas del mismo sexo entró en vigor el 1 de enero de 2009.

- $\quad$ En Suecia, el matrimonio entre personas del mismo sexo entró en vigor el 1 de mayo de 2009.

- $\quad$ En Portugal, la Ley de los matrimonios entre personas del mismo sexo entró en vigor al día 5 de junio del 2010.

- $\quad$ En Islandia, el 11 de junio de 2010, el Parlamento aprobó sin votos en contra (con 49 diputados presentes de un total de 63) la Ley que aprueba el matrimonio igualitario.

- $\quad$ En Argentina, el 15 de julio de 2010 se aprobó el matrimonio entre personas del mismo sexo.

En Dinamarca la Ley que reconoce el matrimonio entre personas del mismo sexo entró en vigor el 15 de junio de 2012.

- $\quad$ En Uruguay el 10 de abril de 2013 se aprobó el proyecto de ley que incluye dentro del matrimonio a las parejas homosexuales.

- $\quad$ En Francia el 17 de mayo de 2013, el Consejo Constitucional de Francia validó la ley de matrimonio entre personas del mismo sexo.

- $\quad$ En Nueva Zelanda la Ley entró en vigor en agosto del 2013.

Finalmente, el matrimonio entre personas del mismo sexo también se ha reconocido en Brasil, Irlanda, Colombia, México y Estados Unidos.

¿Por qué es importante la referencia a la regulación del matrimonio igualitario en la legislación comparada para la resolución de este caso?

Al respecto, el Juzgado, luego de la revisión realizada sobre el tratamiento del matrimonio igualitario en el Derecho Comparado, hace la siguiente reflexión, la misma que, como veremos luego, busca también justificar la decisión tomada: 
Primero, el Juzgado aprecia en base al reconocimiento del matrimonio de personas homosexuales en el mundo, que desde el año 2001, recién se empezó a reconocer dicho derecho a dichas personas, debiendo indicar que nuestro Código Civil data del año 1984, momento en el cual era inimaginable pensar en una institución como la del matrimonio de personas del mismo sexo, razón por la cual el contenido del artículo $234^{\circ}$ de dicho dispositivo legal no fue cuestionado por un largo periodo de tiempo (el subrayado es nuestro).

Segundo, el Juzgado advierte que en vista de los cambios sociales que se han ido presentando, es que considera que dicho artículo del Código Civil no se ha adaptado a los cambios que se han presentado en el mundo, razón por la cual, hoy existe un largo debate sobre si se debe aprobar o no un matrimonio entre personas del mismo sexo (el subrayado es nuestro).

\section{¿La omisión legislativa sobre el matrimonio igualitario $u$ otra figura jurídica análoga, habilita al $7^{\circ}$ Juzgado a emitir un fallo como este?}

Al respecto, el Juzgado considera fundamental tomar en cuenta que a la fecha no existe institución alguna, ya sea matrimonio homosexual, unión civil, u otra institución afín; que proteja o garantice el derecho de las parejas homosexuales a poder efectuar una unión que pueda ser reconocida por el ordenamiento jurídico, reconociéndole así la facultad de poder formar una familia, poder tener derechos sucesorios, y otra serie de derechos de los cuales si gozan las parejas heterosexuales; razón por la cual son un sector de la población que a la fecha se encuentra desprotegido y en constante discriminación, al no habérseles reconocido derecho alguno; partiendo de la realidad de que existen dichas parejas en convivencia, y de que es su deseo protegerse el uno al otro (el subrayado es nuestro).

Por tanto, refiere el Juzgado, efectuando una interpretación evolutiva de nuestra Constitución Política, se considera que dicho dispositivo legal (es decir, el artículo $234^{\circ}$ del Código Civil) debe ser interpretado conforme a los cambios y exigencias que nuestra sociedad reclama, y al haber quedado demostrado que a la fecha un gran sector de la población exige algún tipo de reconocimiento a las parejas homosexuales, ya sea por medio del matrimonio, unión civil $\mathrm{u}$ otro dispositivo; resulta factible que a falta de existencia de dicha institución, dichas personas puedan reclamar protección de sus derechos fundamentales por la vía judicial en virtud del contenido de nuestra Carta Política, puesto que no pueden estar a la espera de que se legisle a favor de ellos (el subrayado es nuestro). 
En otras palabras, el Juzgado considera que no es admisible que se sigan produciendo violaciones a los derechos de las parejas homosexuales, durante el tiempo que tome aprobar una Ley que reconozca estos derechos, debiendo precisarse además, que existe aún incertidumbre con respecto a si en el Perú, se reconocerá o no derecho alguno a favor de estas parejas en un futuro inmediato, ya que esa situación, ha sido justamente la que ha ocasionado que en este caso concreto se vulneren derechos constitucionales reconocidos en el artículo $2^{\circ}$ de la Constitución Política como: el derecho a la igualdad, dignidad, libre desarrollo de la personalidad, entre otros (el subrayado es nuestro).

\section{CONCLUSIONES}

Por lo antes expuesto, queda claro lo siguiente:

1. La Constitución no señala que el único modelo de familia que el Estado deba reconocer es el que está relacionado con el matrimonio

2. El matrimonio igualitario no atenta contra la familia, mucho menos pone en peligro la supervivencia de la especie humana, como algunos sectores ultraconservadores maliciosamente sostienen

3. No existen argumentos constitucionales válidos para oponerse a la aprobación de una Ley que reconozca el matrimonio igualitario en el Perú.

\section{REFERENCIAS}

Constitución Política del Perú de 1993, Congreso de la República: Edición Oficial.

Código Civil peruano - Decreto Legislativo Nº 295 (25 de Julio de 1984) Diario Oficial "El Peruano". Lima, Perú: Ministerio de Justicia.

Tribunal Constitucional, sentencia 0657-2006 - PA/TC.

Fecha de recepción: 31 de agosto de 2017

Fecha de aceptación: 20 de setiembre de 2017 